\title{
MERCURY RETROGRADE EFFECT IN CAPITAL MARKETS: TRUTH OR ILLUSION?
}

\author{
Aurora MURGEA 1 \\ DOI: 10.1515/tjeb-2016-0004 \\ From the most ancient times, the astrological beliefs have \\ played an important role in human history, thinking, \\ world-views, language and other elements of social \\ culture. The practice of relating the movement of celestial \\ bodies to events in financial markets is relatively newer \\ but despite the inconsistency between financial astrology \\ and standard economic or financial theory, it seems to be \\ largely spread among capital market traders. This paper \\ evaluates one of the astrological effects on the capital \\ market, more precisely the Mercury retrograde effect on \\ US capital market. Despite the fact that it is just an optical \\ illusion the astrological tradition says that Mercury \\ retrograde periods are characterized by confusion and \\ miscommunications. The trades could be less effective, \\ the individuals more prone to make mistakes so there is a \\ long-held belief that it is better to avoid set plans during \\ Mercury retrograde, signing contracts, starting new \\ ventures or open new stock market positions. The main \\ findings of this study are lower return's volatilities in the \\ Mercury retrograde periods, inconsistent with the \\ astrologic theories assumptions but consistent with the \\ idea that trader's beliefs in Mercury retrograde effect \\ could change the market volatility exactly in the opposite \\ sense than the predicted one.
}

Keywords: $\quad$ Beliefs, Behavior, Mercury retrograde, Returns, Volatility.

JEL Classification: G02, G10, D53.

\footnotetext{
${ }^{1}$ Associate Professor, Department of Finance, Faculty of Economics and Business Administration, West University of Timisoara, Romania.
} 
Murgea A. (2016).

Mercury retrograde effect in capital markets: truth or illusion?

\section{Celestial Bodies, Mood and Decision}

Science or pseudo-science as its critics are denoting it, astrology has very deep roots in the history of mankind. Among the first things a child says there is a question: "why?" (why does the sun shine, why there is night and day, why we are so different, why we express our feelings so diversely, why do things happen even when one cannot see a reason for them...?) Probably one of the reasons why the astrology has played such an important role in history is because it attempts to bring answers to these questions and more than that it provides a set of forecasting techniques and tools people have always desired ${ }^{1}$.

The important question that arises is: what is the channel used to influence human decision? Psychological and medical studies have linked the celestial bodies' position and evolution stage to decision using the mood channel and the biorhythm ${ }^{2}$ as a mood determinant.

Mood and potential changes of mood seem to influence decision making and securities prices both through cognitive-evaluation and risk-tolerance.

Good mood increases the ability of categorization, creativity in response-generation tasks and efficiency in solving multi-attribute decision problems (Pham, 2007) but individuals in positive mood tend to rely on stereotypes and judgmental heuristics and have a higher propensity to optimism and overconfidence biases (Hoffrage, 2004). A negative mood seems to produce different effects depending on its cause. For instance, sadness decreases the use of scripts and stereotypes and triggers a more systematic, data-driven form of reasoning since sad moods represent a signal for the individual that a more vigilant form of processing is required (Schwarz, 2002). Anger and disgust lead to heuristic rather than systematic processing (Triedens \& Linton, 2001).

${ }^{1}$ Its beginnings are associated with the first attempts to measure, record and predict seasonal changes by reference to astronomical cycles, made by human beings Burckhardt (1969). Babylonian astrology was the first organised system of astrology, dated in the $2^{\text {nd }}$ millennium $B C$ even if there are some isolated references regarding other similar forms that appeared in the Sumerian period in $3^{\text {rd }}$ millennium BC (Holden, 1996). The astrology evolution as a science was not smooth at all. Despite the fact that until the $17^{\text {th }}$ century, astrology was considered a scholarly tradition, commonly accepted in political and cultural circles, meteorology and medicine, by the end of $17^{\text {th }}$ century due to the advances in astronomy, it lost its academic standing (Barton, 1994). If until the $17^{\text {th }}$ century astrology was widely recognized, nowadays people are more afraid of mockery and pretend not to believe in it. Still, the number of the ones who admit that astrology plays an important role in their life and decision is not that small: Pew Research Center (2009) determine, based on a survey study, that more than $25 \%$ from Americans believe in astrology.

2 The idea of different biorhythm cycles that influence human behaviour can be traced back to the German surgeon Wilhelm Fliess in the 1890s who proposed a 23-day male period and a 28-day female period (in Hines, 1988).

DE GRUYTER OPEN
Timisoara Journal of Economics and Business | ISSN: 2286-0991 | www.tjeb.ro Year 2016 | Volume 9 | Issue 1 | Pages: 49-61 
Murgea A. (2016).

Mercury retrograde effect in capital markets: truth or illusion?

The link between mood and risk taking it is still a controversial topic due to the quite opposite theories from the literature: Mood Maintenance Hypothesis (MMH) proposed by Isen, Nygren,\& Ashby (1988) and Affect Diffusion Model (AIM) proposed by Forgas (1995).

The MMH model starts from the idea that the main goal of any individual is to achieve and maintain a state of well-being. If the individual experiences a good mood state, he will avoid risky situations in order to preserve the good state. In the case of a bad mood situation, the individual will choose riskier alternatives hoping that the possible gains will lift his spirit. The effect of human sentiment on the decision making process is also analyzed by Forgas (1995) but the direction of the supposed effect is opposite. The AIM model suggests instead that subjects in bad mood have a more pessimistic view of the world, perceive situations as riskier, and have, as a result, a lower propensity toward risk taking. On the other hand, individuals in a positive affective state, who usually have a more optimistic view and perceive a safer environment, should be more prone to risk taking.

One could think that those two theories cannot be both true, but in fact they can. Individuals are pretty different; hence, the impact of changes of mood may have heterogeneous effects on the risk taking attitude. The relation between mood and risk taking is influenced by several factors such as gender, age, genetic heritage, functioning of the endocrine system and personality traits (for more details see Murgea, 2014).

Among mood determinants, biorhythm seems to play a pretty important role. Recent studies identified three different biorhythm cycles: a 23-day cycle influences physical aspects such as energy, resistance to disease, endurance; a 28-day cycle influences emotions such as sadness, elation, moodiness, creativity and a 33-day cycle influences intellectual functions such as alertness, memory and reasoning ability.

Great attention has been paid to what influence human biorhythm. Among those, the sun, the lunar cycle and the position of other planets have been proved to be among the main factors. As a direct result our biological balances are influenced, the adaptation mechanisms are impaired and the appearance of different mood disorders, especially depression and anxiety, is facilitated affecting also the decision mechanism.

In this framework, the present paper aim is to assess the influence of planet Mercury the smallest and closest to the Sun, on the American capital market. The topic may seem peculiar the first sight since from our knowledge there is no scientific literature, neither psychological nor medical, neither financial to connect the Mercury retrograde with mood or capital market evolution. Despite that, there is a huge tendency among traders to considerate that in the periods when Mercury is retrograde they should avoid important decisions due to a higher market volatility and instability. Considering this, the aim of the paper is to see if there is a 
Murgea A. (2016). of Economics and Business

Mercury retrograde effect in capital markets: truth or illusion?

connection between Mercury retrograde and American markets returns and, if there is something like this how one can explain it.

The paper is structured as follows: the second section explains the use of financial astrology in capital markets, presents the former studies that connect the celestial bodies evolutions with the capital markets evolutions and offers some astrological explanations regarding the Mercury retrograde, the third section is dedicated to the data, methodology and result, the fourth section discusses the results and concludes.

\section{Financial Astrology, Behavioral Finance and Capital Market Evolutions}

\subsection{Financial astrology and trading activities}

The use of astrology in capital market analysis is both complex and controversial. It's a proven fact that the sun, the moon, and other heavenly bodies affect the amount of serotonin in your brain and further the mood. According to Bonner \& Rajiva (2007) this makes astrology a potential useful tool for predicting stock market trends.

The first attempt to use financial astrology belongs to a well-known trader in 1950 s, W. D. Gann, who used a strategy based on the Jupiter-Saturn cycle, to facilitate his trading activities. He considered that since Jupiter and Saturn are the biggest planets in our solar system, they have one of the strongest influences when they are in line. The gravitational pull created determines the Sun to shift periodically. This shift generates weather changes, mood changes and in the final fluctuations in securities prices (Colby, 2003).

Nowadays, since astrology is no longer considered a science, the interest in the subject has moved from the academia to technical analysts, but the interest is in some of the cases kept secret3, because of the fear of mockery. The most prominent technical analysts who use astrology in their trading strategies are Arch Crawford and Bill Meridian. Arch Crawford has been named "Wall Street's best known astrologer" by Barron's Financial Weekly being famous both for calling the Crash of ' 87 months in advance and for the correct prediction of the bear markets in July 1990 and March 2000 (Colby, 2003). Bill Meridian is a very well-known researcher, fund manager, and designer of analytical software able to compute correlations between time series data and planetary cycles (Lo \& Hasanhodzic, 2011). Lately, further literature makes the connection between the movement of planets and the market volatility and lays out the principles that allow the trader to properly use the tools of financial astrology (a very good example in this sense is Pasavento \& Smoleny, 2015).

\footnotetext{
3 Large firms as J.P. Morgan refuse to make comments regarding this practice but the founder, John Pierpont Morgan has personal astrologer. Also his remark on this topic remains famous: "Millionaires don't use astrologers, but billionaires do" in Kleinfield, 1988.
}

\section{DE GRUYTER OPEN}

Timisoara Journal of Economics and Business | ISSN: 2286-0991 | www.tjeb.ro Year 2016 | Volume 9 | Issue 1 | Pages: 49-61 
Murgea A. (2016).

Mercury retrograde effect in capital markets: truth or illusion?

Financial astrology uses different instruments and tools to forecast capital markets cycles according with the celestial bodies' cycles. One of the most known cycles among the astrotraders is the one of the retrograde Mercury. Three times per year, as seen from the Earth, Mercury appears to slow down in its progress through the zodiac, stop and move backward (retrograde). Despite the fact that it is just an optical illusion the astrological tradition says that Mercury retrograde periods are characterized by confusion and miscommunications. The trades could be less effective, the individuals are more prone to make mistakes so there is a long-held belief that it is better to avoid set plans during Mercury retrograde, signing contracts, forming partnerships, starting new ventures or open new stock market positions. While some astrotraders prefer to step aside from active trading and avoid the markets altogether while Mercury is retrograde some others prefer to try to use it for Mercury retrograde based strategies since in many cases Mercury retrograde periods coincide with trend reversals or with short-term countertrends in the context of broader market moves (a very good example in this sense could be depicted from Bost, 2012).

\subsection{The moon, the sun and capital market returns}

During the last decades several behavioral finance studies have tried to prove the presence of a connection between moon cycles, sun and evolution and capital markets.

The belief that the moon exerts an influence on human behavior is widespread both among specialists and the general public, in spite of the little empirical evidence from psychology and medicine. Vance (1995) reported that $81 \%$ of mental health professionals believe that full moon alters individual behavior. Out of the eight moon phases observed by Galileo Galilei both superstitious beliefs and academic studies take into consideration only two: full moon and new moon. Due to the extra-light the full moon produces, the quantity and quality of sleep is prone to decrease. This leads to various behavioral changes, including mania through sleep deprivation. Conforming to Hippocrates's view that" no physician should be entrusted with the treatment of disease who was ignorant of the science of astronomy" (White, 1914), several studies claim that moon alters human behavior and increases the propensity for violence, suicides, accidents and aggression (Thakur et al., 1987; Hicks et al., 1992). On the other hand, no influence of the moon phases was found in any of the following studies, investigating the frequency of calls reporting disturbing behavior (Byrnes \& Kelly, 1992), suicidal tendency (Mathew et al., 1991; Martin et al., 1992), hospital admission due to mental health emergencies and antisocial behavior (Adamou, 2001), increase in incidence and severity of traumatic injuries (Coates et al., 1989), madness (losif \& Ballon, 2012).

Based on these findings, several researchers attempted to find a connection between fool moon and capital markets. Dichev \& Janes (2003) observe lower returns around the full moon due to the heightened risk-aversion and more pessimistic prospects of future cash-flows, in US market and 24 other countries over a 30-year period. The findings by Dichev \& Janes (2003) are

DE GRUYTER OPEN
53

Timisoara Journal of Economics and Business | ISSN: 2286-0991 | www.tjeb.ro

Year 2016 | Volume 9 | Issue 1 | Pages: 49-61 
Mercury retrograde effect in capital markets: truth or illusion?

basically confirmed in Yuan et al. (2006), Nissim et al. (2012). Yuan et al. (2006) state that lunar effect is independent of announcements of macroeconomic indicators, global shocks or other calendar related anomalies, but that it is stronger for emerging economies.

By contrary, Gerlach (2007) finds a lunar pattern in the US market, with higher returns associated with full moon days, mainly due to the announcement days. The same correlation line is found by Liu (2009), who shows that for most of his sample of emergent Asian economies the full moon effect determines not lower but higher returns, whereas they are inversely related to company size in the US case.

The sun effect can be seen in several studies but the connection with capital markets is less direct than the one with the moon. The sunshine effect, the impact of geomagnetic storms (a geomagnetic storm consists in a temporary disturbance of the Earth's magnetosphere determined by an interaction between a strong solar wind shock wave and the Earth's magnetic field) and Seasonal Affective Disorder (Photoperiod (the number of hours of daylight is connected with the seasonal affective disorder - SAD, a subtype of depression characterized by changes in mood, energy, sleep, eating habits and social activities at the change of season) are just several lines of analysis for this effect.

The sunshine effect on mood is widely discussed (Cunningham, 1979; Persinger \& Levesque, 1983; Parrott \& Sabini, 1990). Denissen et al. (2008) find a significant negative effect of temperature, wind power and sunlight on mood. The main explanation offered for the negative effect of sunlight may be due to the role vitamin D3 (produced when the skin is exposed to sunlight) plays in changing the serotonin level in the brain (Lambert et al., 2002).

Krivelyova \& Robotti (2003) analyzed the impact of geomagnetic storms on stock market returns in nine countries, channeled by depression and anxiety. The main results have pointed out that, especially in the small capitalization stocks, geomagnetic storms seem to have a profound effect on risk aversion and indirectly to equity returns. The same results regarding the impact of geomagnetic storms on risk were confirmed by Dowling \& Lucey (2008b) on an extended sample of 37 countries.

Finance researchers have tried to establish a relation between the number of hours of daylight and equity returns based on psychological evidences. Through the link between SAD and depression and between depression and lowered risk aversion, Kamstra et al. (2003) find that seasonal depression, in a nine countries sample, is strongly linked to seasonal variations in stock returns. Dowling \& Lucey (2005) found a correlation, between Irish equity returns and SAD but only between the Winter Solstice and the Spring Equinox. Testing SAD effect on the UK stock market Dowling \& Lucey (2008a), have found evidences of a SAD effect for the UK Small Index and in the opposite direction for the UK Main Index. In another study realized on a sample of 37 
Mercury retrograde effect in capital markets: truth or illusion?

countries, a SAD effect for small caps is also found (Dowling \& Lucey, 2008b) but the effect is more pronounced for countries which are farther away from the equator.

Considering financial astrology practice on the one side and the consistent body of behavioral finance literature regarding moon and sun effect on the other side, we decided to test the presence of abnormal returns in US capital market during the Mercury retrograde periods and to see if the traditional astrologic explanation could fit the empirical results.

\section{Data, Methodology and Results}

To investigate the presence of abnormal differences in returns in the Mercury retrograde periods we have chosen two of the most important indices on American stock market: DJIA and S\&P 500, on a period that range between $1^{\text {st }}$ of February 1993 to 31 ${ }^{\text {st }}$ December 2012.

The market has been chosen considering two very important factors. On the one side, USA capital market is one of the most efficient capital markets and in theory this kind of calendar effect should be less present but, on the other side, the financial astrology field is more developed here than in any other part of the world. Those two arguments make USA a very good case for our study.

The closing prices were computed in daily returns and tested for stationarity with Augmented Dickey-Fuller, Elliott-Rothenberg-Stock DF-GLS and Phillips-Perron test. The results show that none of them have unit roots (tests results available at request).

As a proxy for Mercury retrograde effect we have chosen, according with previous behavioral finance studies that analyzed other celestial bodies influence in capital markets, to use dummy variables computed as follows:

DMR $\left\{\begin{array}{l}1 \text { for the Mercury retrogrades days } \\ 0 \text { for the other days }\end{array}\right.$

The main hypothesis we intend to test could be formulated as follows:

H1: The mercury retrograde periods are indeed characterized by higher market volatility and as a consequence the traders should adapt their strategies according to their willingness to bear this extra risk for a potential supplementary return

or

H2: The mercury retrograde periods are characterized by lower market volatility as a consequence of the trader beliefs in mercury retrograde and their market avoidance during those periods. 
Murgea A. (2016). of Economics and Business

Mercury retrograde effect in capital markets: truth or illusion?

The main assumption of the proposed model is that the current difference in return depends both on the previous return but also on the past differences because the investors are usually tempted to perceive high volatilities as a sign of an enhanced risk. Their attitude in front of this perception will be translated in further trades which will in the final increase the gap of returns. Thus, the proposed model considers the dynamic character of return series and has the following specifications:

$$
D R_{n} \text { Index }_{t}=c+\beta R \text { Index }_{t-1}+\sum_{n=2}^{m} \alpha_{n} D R_{n} \text { Index }_{t}+\gamma D M R_{t}+\varepsilon_{t}
$$

where:

$$
\begin{aligned}
& \mathrm{C}=\text { constant } \\
& \text { RIndex }=\text { (index closing price } t \text {-index closing price } t-1) / \text { index closing price } t-1 \\
& \mathrm{DR}_{\mathrm{n}} \text { Index }_{\mathrm{t}}=\text { RIndex }_{\mathrm{t}}-\text { RIndext-n }_{\mathrm{t}} \\
& \mathrm{DMR}_{\mathrm{t}}=\text { dummy variable for Mercury retrograde } \\
& \beta, \alpha, \gamma=\text { importance coeficients } \\
& \varepsilon_{t}=\text { standard error }
\end{aligned}
$$

For the two indices the formulas, using the same algorithm, become:

$$
D R_{1} D J I A_{t}=c+\beta R D J I A_{t-1}+\sum_{n=2}^{m} \alpha D R_{n} D J I A_{t}+\gamma D M R_{t}+\varepsilon_{t}
$$

and

$$
D R_{1} S_{-} P 500_{t}=c+\beta R S_{t-1}+\sum_{n=2}^{m} \alpha D R_{n} \text { Index }_{t}+\gamma D M R_{t}+\varepsilon_{t}
$$

\begin{tabular}{|c|c|c|c|c|}
\hline \multirow{2}{*}{ Variables } & \multicolumn{4}{|c|}{ Coefficients } \\
\hline & Model 1 & Model 2 & Model 3 & Model 4 \\
\hline C & $\begin{array}{c}0.000364 * * * \\
(0.000125)\end{array}$ & $\begin{array}{c}0.000376 * * * \\
(0.000102)\end{array}$ & $\begin{array}{c}0.000374 * * * \\
(0.000008)\end{array}$ & $\begin{array}{c}0.000367 * * * \\
(0.000007)\end{array}$ \\
\hline RDJIA(-1) & $\begin{array}{c}-1.058996 * * * \\
(0.009733)\end{array}$ & $\begin{array}{c}-1.054544 * * * \\
(0.007899)\end{array}$ & $\begin{array}{c}-1.034967 * * * \\
(0.006716)\end{array}$ & $\begin{array}{c}-1.028729 * * * \\
(0.005907)\end{array}$ \\
\hline DMR & $\begin{array}{l}-0.000387 \\
(0.000280)\end{array}$ & $\begin{array}{c}-0.000451 * * \\
(0.000227)\end{array}$ & $\begin{array}{c}-0.000465 * * \\
(0.000193)\end{array}$ & $\begin{array}{c}-0.000438 * * * \\
(0.000169)\end{array}$ \\
\hline D2RDIA & $\begin{array}{c}0.499994 * * * \\
(0.006733)\end{array}$ & $\begin{array}{c}0.349084 * * * \\
(0.006214)\end{array}$ & $\begin{array}{c}0.263288 * * * \\
(0.005618)\end{array}$ & $\begin{array}{c}0.200492 * * * \\
(0.005205)\end{array}$ \\
\hline
\end{tabular}

where RDJIA and RS_P500 stand for the daily return of DJIA and daily return of S\&P500.

Testing the following benchmark, we noticed that the former five differences in returns are significant for the present differences in return. The quality of the model increases when more past differences are introduced (from model 1 to model 4) as one could see in the next two tables because the present volatility is better explained by a longer volatilities history.

Table 1. Regression results for DJIA

DE GRUYTER OPEN
Timisoara Journal of Economics and Business | ISSN: 2286-0991 | www.tjeb.ro Year 2016 | Volume 9 | Issue 1 | Pages: 49-61 
Murgea A. (2016). of Economics and Business

Mercury retrograde effect in capital markets: truth or illusion?

\begin{tabular}{|c|c|c|c|c|}
\hline \multirow{2}{*}{ Variables } & \multicolumn{4}{|c|}{ Coefficients } \\
\hline & Model 1 & Model 2 & Model 3 & Model 4 \\
\hline D3RDIAA & & $\begin{array}{c}0.327584 * * * \\
(0.006428)\end{array}$ & $\begin{array}{c}0.251032 * * * \\
(0.005721)\end{array}$ & $\begin{array}{c}0.203464 * * * \\
(0.005182)\end{array}$ \\
\hline D4RDIAA & & & $\begin{array}{c}0.251695 * * * \\
(0.005701)\end{array}$ & $\begin{array}{c}0.206689 * * * \\
(0.005147)\end{array}$ \\
\hline D5RDIA & & & & $\begin{array}{c}0.199311 * * * \\
(0.005200)\end{array}$ \\
\hline R-squared & 0.776210 & 0.852723 & 0.894064 & 0.918150 \\
\hline Adjusted R-squared & 0.776075 & 0.852605 & 0.893958 & 0.918052 \\
\hline Akaike info criterion & -6.838981 & -7.256777 & -7.585673 & -7.843077 \\
\hline Schwarz criterion & -6.833774 & -7.250266 & -7.577859 & -7.833959 \\
\hline F-statistic & 5784.248 & 7238.857 & 8437.941 & 9342.276 \\
\hline Prob (F-statistic) & 0.000000 & 0.000000 & 0.000000 & 0.000000 \\
\hline No of observations & 5007 & 5006 & 5005 & 5004 \\
\hline
\end{tabular}

* stands for a probability that ranges from 0.1 to 1

** stands for a probability that ranges from 0.05 to 0.1

*** stands for a probability that ranges from 0 to 0.05

Table 2. Regression results for S\&P500

\begin{tabular}{|c|c|c|c|c|}
\hline \multirow[b]{2}{*}{ Variables } & \multicolumn{4}{|c|}{ Coefficients } \\
\hline & Model 1 & Model 2 & Model 3 & Model 4 \\
\hline C & $\begin{array}{c}0.000323 * * * \\
(0.000132)\end{array}$ & $\begin{array}{c}0.000330 * * * \\
(0.000106)\end{array}$ & $\begin{array}{c}0.000328 * * * \\
(0.000009)\end{array}$ & $\begin{array}{c}0.000320 * * * \\
(0.000007)\end{array}$ \\
\hline RS_P500(-1) & $\begin{array}{c}-1.067676 * * * \\
(0.0000)\end{array}$ & $\begin{array}{c}-1.060158 * * * \\
(0.007830)\end{array}$ & $\begin{array}{c}-1.042578 * * * \\
(0.006641)\end{array}$ & $\begin{array}{c}-1.035558 * * * \\
(0.005821)\end{array}$ \\
\hline DMR & $\begin{array}{c}-0.000382 \\
(0.1960)\end{array}$ & $\begin{array}{l}-0.000426 * \\
(0.000238)\end{array}$ & $\begin{array}{c}-0.000431 * * \\
(0.000202)\end{array}$ & $\begin{array}{c}-0.000400 * * \\
(0.000177)\end{array}$ \\
\hline D2RS_P500 & $\begin{array}{c}0.499980 * * * \\
(0.0000)\end{array}$ & $\begin{array}{c}0.347300 * * * \\
(0.006157)\end{array}$ & $\begin{array}{c}0.261366 * * * \\
(0.005618)\end{array}$ & $\begin{array}{c}0.200596 * * * \\
(0.005115)\end{array}$ \\
\hline D3RS_P500 & & $\begin{array}{c}0.329714 * * * \\
(0.006324)\end{array}$ & $\begin{array}{c}0.254023 * * * \\
(0.005618)\end{array}$ & $\begin{array}{c}0.204871 * * * \\
(0.005082)\end{array}$ \\
\hline D4RS_P500 & & & $\begin{array}{c}0.250420 * * * \\
(0.005631)\end{array}$ & $\begin{array}{c}0.206370 * * * \\
(0.005061)\end{array}$ \\
\hline D5RS_P500 & & & & $\begin{array}{c}0.198948 * * * \\
(0.005111)\end{array}$ \\
\hline R-squared & 0.778452 & 0.856469 & 0.897160 & 0.921091 \\
\hline Adjusted R-squared & 0.778319 & 0.006734 & 0.897057 & 0.920997 \\
\hline Akaike info criterion & -6.728703 & -7.162209 & -7.495013 & -7.759297 \\
\hline Schwarz criterion & -6.723496 & -7.155698 & -7.487199 & -7.750180 \\
\hline F-statistic & 5859.673 & 7460.412 & 8722.096 & 9721.562 \\
\hline Prob (F-statistic) & 0.000000 & 0.000000 & 0.000000 & 0.000000 \\
\hline No of observations & 5007 & 5006 & 5005 & 5004 \\
\hline
\end{tabular}

* stands for a probability that ranges from 0.1 to 1

** stands for a probability that ranges from 0.05 to 0.1

*** stands for a probability that ranges from 0 to 0.05 
Mercury retrograde effect in capital markets: truth or illusion?

Also, for both indices, there is a statistically significant negative correlation between Mercury retrograde periods and return's volatility, inconsistent with the astrological theories.

The interesting fact is that, despite this inconsistency, the traders "beliefs in Mercury retrograde could be the determinant of this reduced volatility. Their tendency to avoid trading in this period could reverse in fact the market trend predicted by astrological theories (in theory Mercury retrograde period should be characterized by an increased return volatility, to fit with the assumptions that in those periods trend reversals or short-term counter-trends in the context of broader market moves may occur).

\section{Final Remarks}

The results seem to be inconsistent with the idea of trends reversals from the astrological theories connected with Mercury retrograde. The regressions coefficients show a negative not very strong, but statistically significant correlation between the return's volatility and the dummy variable in the periods when Mercury seems to go backwards.

Several possible explanations could back up these results. First, as any other anomaly on the capital market, as long as the market already knows about it there is a strong possibility for it to be attenuated, to reverse or even to disappear (Schwert, 2003). Mercury retrograde oriented strategy may in time reverse the process as long as the traders which apply them prevail on the market. Second, even if there is not such an influence, only the trade absence which often characterizes the traders in this period could lead to a lower volatility in market returns. In a new research, Anginer et al. (2015) offer empirical proof that the predictive ability of anomalies usually survive when the direction of insider trading agrees with the anomaly but completely disappears in the opposite case.

Another supplementary explanation could be associated with market environment changes as improved liquidity, increased number and traded volumes of the institutional investors, decreased trading costs and expanded regulations and information disclosure (Fu \& Huang, 2015).

In any case the result of the present study points out that the market does not evolve as the astrological theories state but the belief in a strong volatility during Mercury retrograde periods could be in fact one of the important reasons why the market shows a lower volatility in those periods.

The findings of the present study could be extremely useful both for the capital markets individual and institutional investors because anomaly-based strategies could be created using the results. In a market where a lot of participants restrain themselves from trading in Mercury retrograde period a smart investor could use this trend in his favor.

DE GRUYTER OPEN 


\section{References}

Adamou, M. (2001). Relationship of the lunar cycle and the presentation of individuals with psychiatric problems to an accident and emergency department: a case - control study. International Journal of Psychiatry in Clinical Practice, 7, 115-116. doi: 10.1185/135525701317094476.

Anginer, D., Hoberg, G., \& Sevhun, H.N. (2015). Can Anomalies Survive Insider Disagreements? Retrieved from: http://dx.doi.org/10.2139/ssrn.2625614.

Ankerberg, J., \& Weldon, J. (2011). Astrology do the heavens rule our destiny, New York: ATRI Publishing.

Barton, T. (1994). Ancient Astrology, New York: Routledge.

Bonner, W., \& Rajiva, L. (2007). Mobs, Messiahs, and markets: Surviving the public spectacle in finance and politics, New Jersey: John Wiley \&Sons.

Bost, T. (2012). Mercurv, monev and the markets: profitable planetary cycles for short term astra-trading, Palmeto: Harmonic Research Associates.

Burckhardt, T. (1969). The Seven Liberal Arts and the West Door of Chartres Cathedral, Studies in Comparative Religion, 3(3). Retrieved from: www.studiesincomparativereligion.com.

Byrnes, G., \& Kelly, I. (1992). Crisis calls and lunar cvcles: a 20 - year review. Psychological Reports, 71, 779-785. doi: 10.2466/pr0.1992.71.3.779.

Coates, W., Jehle, D., \& Cottinghton, E. (1989).Trauma and the full moon: a waning theory. Annals of Emergency Medicine, 18, 763-765. doi: 10.1016/S0196-0644(89)80014-9.

Colby, R. W. (2003). The Encyclopedia of Technical Market Indicators, Second Edition CMT, Columbus: McGraw-Hill Publishing.

Cunningham, M.R. (1979). Weather, mood and helping behavior: Quasi-experiment with the sunshine samaritan. Journal of Personality and Social Psychology, 37, 1947-1956. doi: 10.1037/0022-3514.37.11.1947.

Denissen, J.J.A., Butalid, L., Penke, L., \& Van Aken, M.A. (2008). The effects of weather on daily mood: a multilevel approach. Emotion, 8, 662-667. doi: 10.1037/a0013497.

De Vries, M., Holland, R. W., Corneille, O., Rondeel, E., \& Witteman, C.L. (2010). Mood effects in dominated choices: positive mood induces departures from logical rules. Journal of Behavioral Decision Making, 25(1), 74-81. doi: 10.1002/bdm.716.

Dichev, I.D. \& Janes, T.D. (2003). Lunar cycle effects in stock returns. Journal of Private Equity, 6, 8-2. doi: 10.3905/jpe.2003.320053.

Dowling,M. \& Lucey,B.M. (2005). Weather, biorhythms, beliefs and stock returns - Some preliminary Irish evidence. International Review of Financial Analysis, 14, 337-355. doi: http://dx.doi.org/10.1016/j.irfa.2004.10.003.

Dowling, M, \& Lucey, B.M. (2008a). Mood and UK equity pricing. Applied Financial Economics Letters, 4, 233 - 240. doi: 10.1080/17446540701720584.

Dowling, M, \& Lucey, B.M. (2008b). Robust global mood influences in equity pricing. Journal of Multinational Financial Management, 18 , 145-164. doi: 10.1016/j.mulfin.2007.06.002.

DE GRUYTER OPEN
Timisoara Journal of Economics and Business | ISSN: 2286-0991 | www.tjeb.ro Year 2016 | Volume 9 | Issue 1 | Pages: 49-61 
Murgea A. (2016).

Mercury retrograde effect in capital markets: truth or illusion?

Forgas, J.P. (1995). Mood and judgment: the effect infusion model (AIM). Psychological Bulletin, 117, 39-66. Retrived from: http://dx.doi.org/10.1037/00332909.117.1.39.

Fu, F., \& Huang, S. (2015). The Persistence of Long-Run Abnormal Returns Following Stock Repurchases and Offerings. Management Science. Research Collection Lee Kong Chian School Of Business. Retrived from: http://dx.doi.org/10.1287/mnsc.2015.2150.

Gerlach, J.R. (2007). Macroeconomic news and stock market calendar and weather anomalies. The Journal of Financial Research, 30, 283-300. doi: 10.1111/j.14756803.2007.00214.x.

Hicks-Caskey, W.E. \& Potter, D.R. (1992). Weekends and Holidays and Acting-out Behavior of Developmentally Delaved Women: A Replv to Dr. Mark Flynn. Perceptual and Motor Skills, 74, 344-346. doi: 10.2466/pms.1992.74.2.344.

Hines, T.M. (1988). Comprehensive review of biorhythm theory. Psychological Reports, 83, 19-64. doi: 10.2466/pr0.1998.83.1.19.

Holden, J.H. (1996). A History of Horoscopic Astrology from the Babylonian period to the modern age, Tempe:American Federation of Astrologers, Inc.

Iosif, A. \& Ballon, B. (2012). Bad mood rising: the persistent belief in lunar connection to madness. Canadian Medical Association Journal, 173, 1498-1500.

Hoffrage, U. (2004). Overconfidence. In R.F. Pohl (ed.) Cognitive Illusions: a handbook on fallacies and biases in thinking, judgement and memory). Sutherland: Psychology Press, pp.235-255.

Isen, A.M , Nygren, T.E., \& Ashby, F.G. (1988). Influence of positive affect on the subjective utility of gains and losses: it is just not worth the risk. Journal of Personality and Social Psychology, 55, 710-717. doi: http://dx.doi.org/10.1037/0022-3514.55.5.710.

Kamstra, M.J., Kramer, L.A., \& Levi, M.D.(2003). Winter blues: a SAD Stock market cycle. The American Economic Review, 93, 324-343.

Kahneman, D. \& Tversky, A. (1973). On the psychology of prediction. Psychological Review, 80 (4), 237-251. doi: http://dx.doi.org/10.1037/h0034747.

Kleinfield, N.R. (1988). Seeing dollar signs in searching the stars. New York Times, section3, p.1.

Krivelyova, A., \& Robboti, C. (2003). Playing the field: geomagnetic storms and the stock market. Federal Reserve Bank of Atlanta Working Paper 2003-5b.

Lambert, G.W., Reid, C., Kaye, D.M., Jennings, G.L.,\& Esler, M.D. (2002). Effects of sunlight and season on serotonin turnover in the brain. Lancet 360, 1840-1842. doi:10.1016/S0140-6736(02)11737-5

Liu, S.I. (2002). A Bayesian analysis of lunar effects on stock returns. Retrieved from: http://papers.ssrn.com/sol3/papers.cfm?abstract_id=1366663.

Lo, A.W., \& Hasanhodzic, J. (2011). The evolution of technical analysis. Financial prediction from Babylonian tablets to Bloomberg terminals, New Jersey: John Wiley \& Sons.

Martin, S., Kelly, I., \& Saklofske, D. (1992). Suicide and lunar cvcles: a critical review over 28 years. Psychological Reports, 71, 787-895. doi: 10.2466/pr0.1992.71.3.787.

Mathew, V.M., Lindesay, J., Shanmuganathan, N. \& Eapen, V. (1991). Attempted suicide and the lunar cvcle. Psychological Reports, 68, 927-930. doi: 10.2466/pr0.1991.68.3.927.

Murgea, A. (2014). Investment behaviour. Rationality, news asymmetry and mood misattribution, Saarbrücken: Lambert Academic Publishing. 
Murgea A. (2016).

Mercury retrograde effect in capital markets: truth or illusion?

Nissim, B.D., Liran, L. , \& Eshel,S. (2012). Do natural phenomena affect stocks' yield in Israel? Applied Financial Economics, 22: 127-133. doi: 10.1080/09603107.2011.605753.

Parrott, W.G., \& Sabini, J. (1990). Mood and memory under natural conditions: evidence for mood incongruent recall. Journal of Personality and Social Psychology 59, 321-336. Retrived from: http://dx.doi.org/10.1037/0022-3514.59.2.321.

Pasavento, L., \& Smoleny, S. (2015). A traders guide to financial astrology: forecasting market cycles using planetary and lunar movements, New Jersey: John Wiley \&Sons.

Persinger, M.A., \& Levesque, B.F. (1983). Geophysical variables and behavior: XII: the weather matrix accommodates large portions of variance of measured daily mood. Perceptual and Motor Skills 57, 868-870. doi: 10.2466/pms.1983.57.3.868.

Pew Research Center (2009). Many Americans mix multiple faiths. Retrived from: http://www.pewforum.org/files/2009/12/multiplefaiths.pdf.

Pham, M.T. (2007). Emotion and rationality: a critical review and interpretation of empirical evidences. Review of General Psychology, 11, 155-178. doi: 10.1037/10892680.11.2.155.

Schwarz, N. (2002). Situated cognition and the wisdom of feelings: Cognitive tuning. In L.F.Barrett and P.Salovery (eds.), The wisdom in feelings: Psychological processes in emotional intelligence. New York: Guilford Press, pp.144-166.

Schwert, G.W. (2003). Anomalies and market efficiency in Constantinides, G.M.,. Harris M. and R. Stulz Handbook of the Economics of Finance, Elsevier Science B.V.

Thakur,C.P., Thakur, B., Singh, S., Kumar B. (1987). Relation between full moon \& medicolegal deaths. Indian Journal of Medical Research, 85, 316-320.

Triedens, L.Z., \& Linton, S. (2001). Judgment under emotional certainty and uncertainty: The effects of specific emotions on information processing. Journal of Personality and Social Psychology Bulletin, 81, 973-988. Retrived from: http://dx.doi.org/10.1037/0022-3514.81.6.973.

Vance,D. (1985). Belief in lunar effects on human behavior. Psychological Reports, 76, 32-34. doi: 10.2466/pr0.1995.76.1.32.

White,W. (1914). Moon myth in medicine: the moon as libido symbol. Psychoanalytic Review, 1, 241-256.

Yuan, K., Zheng, L., \& Zhu, Q. (2006). Are investors moonstruck? Lunar phases and stock returns. Journal of Empirical Finance 13: 1-23. doi: 10.1016/j.jempfin.2005.06.001. 